\title{
O PAPEL DA INTER-RELAÇÃO DO VERBO-VISUAL NO GÊNERO ENTREVISTA PINGUE-PONGUE*
}

\section{THE ROLE OF THE VERB-VISUAL INTERRELATION IN THE PING- PONG INTERVIEW GENRE}

\author{
Nivea Rohling da Silva** \\ Rosângela Hammes Rodrigues ${ }^{* * *}$
}

RESUMO: Este artigo analisa a inter-relação das modalidades verbal e visual no gênero entrevista pingue-pongue, tendo como embasamento a teoria dialógica do discurso. Observamos que a articulação entre as modalidades verbal e visual contribui significativamente para a constituição do gênero e do sentido nas entrevistas publicadas. Dentre os elementos pictóricos (fotografia, cor, disposição gráfica dos elementos), a fotografia do entrevistado mostrou-se o mais "saliente" no gênero. Ela é responsável por "atrair" a atenção do leitor, concretizando a interação entre autor e leitor, além de atribuir valoração ao entrevistado e seu discurso.

PALAVRAS-CHAVE: entrevista pingue-pongue, linguagem verbo-visual, gêneros do discurso, Bakhtin.

ABSTRACT: This article analyzes the inter-relation of the verb-visual modalities in the ping-pong interview genre, based on the dialogic theory of discourse. We observed that the articulation between the verbal and visual modalities significantly contributes to the construction of the genre and the sense in the published interviews. Among the pictorial elements (photography, color, graphic disposal of elements), the interviewee's photograph was shown to be the most "remarkable" in the genre. It is responsible for "attracting" the reader's attention, concretizing the interaction between author and reader, as well as valuing the interviewee and his speech.

KEYWORDS: ping-pong interview, verbal-visual language, speech genres, Bakhtin.

* Este trabalho é parte integrante do grupo de pesquisa "Os gêneros do discurso: práticas pedagógicas e análise de gêneros" e do projeto "Estudo dos gêneros do discurso jornalísticos: análises na perspectiva bakhtiniana da linguagem", ambos coordenados pela Prof ${ }^{\mathrm{a}}$. Dr ${ }^{\mathrm{a}}$. Rosângela Hammes Rodrigues (UFSC).

${ }^{* *}$ Doutoranda em Linguística pela Universidade Federal de Santa Catarina, Florianópolis, SC. Bolsista CAPES.niveajoi@yaho.com.br.

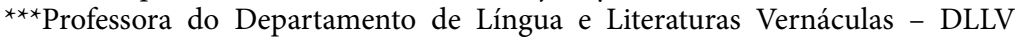
- UFSC, Florianópolis, SC. Doutora em Linguística Aplicada e Estudos da Linguagem pela Pontifícia Universidade Católica de São Paulo. hammes@ cce.ufsc.br 



\section{INTRODUÇÃO}

Este artigo tem por objetivo apresentar uma análise de aspectos relativos à dimensão linguageira do gênero entrevista pingue-pongue, do jornalismo de revista, tendo como enfoque a articulação das modalidades verbal $e$ pictórica (ou visual) nesse gênero.

Para tanto, inicialmente, delinearemos o quadro teórico em que nos inserimos, a teoria de gêneros do discurso do Círculo de Bakhtin, apresentando conceitos centrais para a consecução do objetivo proposto, em especial, os de enunciado e de gêneros do discurso. Em seguida, faremos a descrição dos dados de pesquisa, precedida de breve exposição e justificativa do percurso metodológico escolhido para a análise. Finalmente, apresentaremos aspectos mais gerais da análise do gênero entrevista pingue-pongue e a análise da articulação do verbo-visual, em especial a modalidade pictórica, destacando o papel discursivo que desempenha no gênero analisado.

\section{A CONCEPÇÃO DE ENUNCIADO EM BAKHTIN}

O enunciado é um dos conceitos centrais na teoria do Círculo de Bakhtin, tendo em vista a própria afirmação de Bakhtin a respeito da importância

\footnotetext{
${ }^{1}$ De acordo com o tradutor do livro Estética da criação verbal, Paulo Bezerra, com relação ao enunciado, Bakhtin utiliza um só termo - viskázivanie - para designar tanto a enunciação (emissão do discurso) quanto o enunciado (discurso já pronunciado).
} 
do enunciado nas interações sociais: "Aprender a falar significa aprender a construir enunciados (porque falamos por meio de enunciados e não por orações isoladas e, evidentemente, não por palavras isoladas)." (2003: 283). Segundo Volochinov e Bakhtin ${ }^{2}$ (1926: 9), "o enunciado concreto (e não a abstração lingüística) nasce, vive e morre no processo da interação social entre os participantes da enunciação. Sua forma e significado são determinados basicamente pela forma e caráter desta interação." Para Volochinov e Bakhtin (1926), o enunciado é a expressão e o produto da interação de três participantes, a saber: o falante (autor), o interlocutor (leitor, contemplador, espectador, ouvinte) e o tópico (herói, tema, o que ou quem da fala), constituídos e sulcados pelas relações dialógicas (BAKHTIN, 2003).

Com relação a sua constituição, o enunciado compõe-se de três elementos intrinsecamente ligados: conteúdo temático, estilo e construção composicional. O conteúdo temático, definido pelas atividades humanas, relaciona-se às escolhas do objeto do discurso feitas pelo falante para compor seu discurso. Tais escolhas são realizadas na interlocução; o objeto pode também surgir de outros enunciados, em forma de reação-resposta ativa. A construção composicional, por sua vez, está relacionada à organização textual-discursiva do enunciado e à relação entre os interlocutores, propiciando a noção de acabamento do enunciado. Segundo Bakhtin (2003), uma determinada construção composicional permite que o falante tenha a percepção de conjunto do discurso e até faz com que ele antecipe seu (do enunciado do outro) fim.

Quanto ao estilo, Bakhtin (2003) enfatiza que todo enunciado é individual e, por isso, pode refletir a individualidade do falante na linguagem, mas ressalta que nem todos os gêneros possibilitam a expressão do estilo individualizado; alguns gêneros têm como característica principal a padronização e a eliminação de marcas individuais nos enunciados, como, por exemplo, os gêneros das esferas administrativa, militar e acadêmica. Em resumo, de acordo com Bakhtin (2003: 262), o estilo do enunciado, que se molda ao estilo do gênero, caracteriza-se pela "seleção dos recursos léxicos, fraseológicos e gramaticais da língua".

Ainda no que tangeà caracterização do enunciado, podemos citar algumas características suas como unidade da comunicação discursiva, a saber: o fato de ter contato com a realidade (situação extraverbal [ou extralinguageira]);

\footnotetext{
${ }^{2}$ Sobre a referenciação da autoria dos textos "disputados", optamos por fazer a referência seguindo as indicações dos autores das obras consultadas.
} 
a possibilidade de ser delimitado pela alternância dos sujeitos do discurso; a expressividade e a conclusibilidade (BAKHTIN, 2003).

Segundo concepções do Círculo de Bakhtin, o enunciado, como um todo de sentido, não se limita apenas a sua dimensão verbal (ou linguageira). Para além de uma parte verbal, fazem parte do enunciado, como elementos necessários a sua constituição e a sua compreensão total, outros aspectos constitutivos, que compõem sua dimensão extraverbal, ou a sua dimensão social constitutiva. Essa situação extraverbal do enunciado, de acordo com Volochinov (1926), compreende três fatores: 1) o horizonte espacial e temporal comum dos interlocutores (onde e quando do enunciado); 2) o conhecimento e a compreensão comum da situação por parte dos interlocutores (aquilo de que se fala); e 3) sua avaliação comum dessa situação (atitude dos participantes do discurso face ao objeto do discurso).

$\mathrm{O}$ aspecto da expressividade, resultado dessa atitude avaliativa, igualmente, é considerado uma característica inerente ao enunciado, dado a não existência de enunciados neutros. Portanto, a expressividade está ligada à posição axiológica do autor frente ao objeto do seu discurso e aos interlocutores da interação.

A alternância dos sujeitos do discurso, que termina com a transmissão da palavra ao outro, caracteriza-se por fixar "os limites de cada enunciado concreto como unidade da comunicação discursiva" (BAKHTIN, 2003: 175). Compreendemos que essa alternância dos falantes se relaciona às fronteiras do enunciado, em outras palavras, o enunciado do outro serve de limite para o meu próprio enunciado. Na interação verbal, os sujeitos se intercalam na enunciação, produzindo enunciados que requerem reações-respostas ativas. Nessa troca, evidencia-se o caráter dialógico dos enunciados. A alternância dos sujeitos do discurso (limite do enunciado) constitui-se em um dos primeiros critérios que emprestam ao enunciado o status de unidade real da comunicação discursiva e que o caracterizam como um elo na cadeia de muitos outros enunciados, produzindo uma teia de significações. "É esse limite que 'emoldura' o enunciado e cria para ele a massa firme." (BAKHTIN, 2003: 279).

Já a conclusibilidade, por sua vez, confere ao enunciado o caráter de acabamento; ela parte, primeiramente, da possibilidade responsiva do interlocutor. Esse fechamento, que faz com que o enunciado seja compreendido e passível de resposta, não se apresenta gramaticalmente, mas sim através de interações reais entre os sujeitos do discurso (BAKHTIN, 2003). 
Na explanação sobre a conclusibilidade, Bakhtin afirma que ela é

uma espécie de aspecto interno da alternância dos sujeitos do discurso; essa alternância pode ocorrer precisamente porque o falante disse (ou escreve) tudo o que quis dizer em dado momento ou sob dadas condições. Quando ouvimos ou vemos, percebemos nitidamente o fim do enunciado, como se ouvíssemos o "dixi" conclusivo do falante (2003: 280).

Tal noção de conclusibilidade, nos termos bakhtinianos, é facilmente verificada em uma conversa cotidiana, em que o falante percebe o fim do enunciado do interlocutor antes mesmo de sua conclusão e, muitas vezes, antecipa sua resposta. Sob essa ótica, o primeiro critério da conclusibilidade é "a possibilidade de responder a ele [ao enunciado], em termos mais precisos e amplos, de ocupar em relação a ele uma posição responsiva" (2003: 208). O autor aponta, como exemplos de posição responsiva, situações como: cumprir uma ordem, o discurso científico com o qual se pode concordar ou não (inteiramente ou em parte) e as repostas a questionamentos feitos no cotidiano, tais como, "Que horas são?" (BAKHTIN, 2003).

$\mathrm{O}$ enunciado, na perspectiva bakhtiniana, apresenta duas facetas: o enunciado na condição de evento (acontecimento) e o enunciado como historicidade. Na condição de evento, o enunciado é "acabado", há um início e um fim que se marca pela alternância dos sujeitos e pela possibilidade de resposta. Enfim, do ponto de vista do acontecimento, o enunciado é único e irrepetível e é um elo na cadeia da comunicação discursiva.

Já o caráter histórico do enunciado, por sua vez, está relacionado à noção de "não-acabamento". Aliás, essa noção está presente no pensamento bakhtiniano não somente no que se refere ao conceito de enunciado, mas, também, no que tange à própria construção da subjetividade do sujeito, pois, este é, para Bakhtin, também inacabado. Em outros termos, o enunciado, em sua historicidade, está ligado dialogicamente a outros enunciados, uma vez que, segundo Bakhtin, "[n]ão pode haver enunciado isolado. Ele sempre pressupõe enunciados que o antecedem e o sucedem. Nenhum enunciado pode ser primeiro ou último. Ele é apenas o elo na cadeia e fora dessa cadeia não pode ser estudado." (2003: 371)

Assim, o conceito bakhtiniano de enunciado mostra-se complexo, podendo somente ser compreendido no plano do discurso e não no plano da língua (sistema de formas), uma vez que é uma unidade do discurso. Até aqui expusemos o conceito de enunciado, que se constitui em um elemento importante para a apreensão da noção de gêneros do discurso, que será o tema da seção seguinte. 


\section{GÊNEROS DO DISCURSO: AS FORMAS DE DISCURSO SOCIAL}

A partir do conceito de enunciado podemos chegar ao conceito de gêneros do discurso postulado pelo Círculo de Bakhtin. Esse conceito é apresentado em muitos textos do Círculo, e sua terminologia oscila entre formas de discurso social, formas de um todo, tipos de interação verbal e tipos de enunciados (RODRIGUES, 2005). Entretanto, no texto intitulado "Os gêneros do discurso" (2003), onde a questão dos gêneros é detalhada, Bakhtin opta pelo termo gêneros do discurso, que acabou sendo também o termo mais utilizado nas pesquisas em Linguística Aplicada hoje em dia. ${ }^{3}$ No referido texto, Bakhtin define os gêneros do discurso como "tipos relativamente estáveis de enunciados", ou seja, através de enunciados individuais, de uma dada situação social de interação de uma determinada esfera social (jornalismo, ciência, escola etc.), que se movimentam em direção a uma regularidade (que é resultado da estabilização dessa situação social de interação), surge o gênero. Uma vez constituído, ele funciona como referência (sua normatividade) para a produção de novos enunciados.

Definidos como tipos relativamente estáveis de enunciados, observamos que os gêneros carregam em si um caráter flexível e plástico e de não acabamento. Nessa definição, a palavra relativamente é fundamental, pois ela acena para a flexibilidade do gênero, a qual está diretamente ligada às interações sociais e para o seu não acabamento. Se as relações humanas são complexas, as mudanças são ininterruptas e os gêneros constituemse a partir das atividades humanas, consequentemente, eles irão refletir as mudanças histórico-sociais. Uma vez que as interações humanas estão em constante constituição, os gêneros possuem, então, a mesma característica de "não-acabamento" das atividades humanas e dos enunciados.

Ainda sobre a conceituação de gêneros, de acordo com Rodrigues, Bakhtin concebe os gêneros como uma "tipificação social dos enunciados

\footnotetext{
${ }^{3}$ Em Rojo (2005), no texto intitulado "Gêneros do discurso e gêneros textuais: questões teóricas e aplicadas", há uma discussão sobre a diferença teórico-metodológica envolvida no uso das terminologias: gêneros do discurso ou discursivos e gêneros de texto ou textuais. Para a autora, o uso de uma ou outra terminologia reflete duas vertentes de pesquisas ancoradas em diferentes leituras (interpretações) da obra do Círculo de Bakhtin e diferentes concepções de gênero. Assim, a distinção está no fato de que a primeira centra seu estudo nas situações de produção dos enunciados ou textos e em seus aspectos sócio-históricos, e a segunda, na descrição da materialidade do texto.
} 
que apresentam certos traços (regularidades) comuns, que se constituíram historicamente nas atividades humanas, em uma situação de interação relativamente estável" (RODRIGUES, 2005: 164). Assim, segundo Rodrigues, é necessário olhar os gêneros a partir de sua historicidade, já que não são unidades convencionais, mas tipos históricos de enunciados, possuindo a mesma natureza do enunciado (natureza social, discursiva e dialógica).

De acordo com Bakhtin (2003), a diversidade dos gêneros é infinita porque são inesgotáveis as possibilidades das atividades humanas e porque cada esfera comporta um repertório de gêneros do discurso que vai se diferenciando e se ampliando à medida que a própria esfera se desenvolve e torna-se mais complexa. Ao estabelecer a noção de gênero, o autor apresenta uma distinção entre os gêneros primários e os secundários. Os gêneros primários são aqueles ligados à esfera cotidiana, como, por exemplo, o gênero bilhete e a conversa cotidiana etc. Já os gêneros secundários, segundo Bakhtin, "surgem nas condições de um convívio cultural mais complexo e relativamente desenvolvido e organizado (predominantemente escrito)" (2003: 263). Em seu processo de constituição, eles reelaboram diversos gêneros primários. São exemplos de gêneros secundários: o romance, os gêneros científicos, como o artigo e a tese, os gêneros jornalísticos, como a notícia, o editorial e a resenha, entre outros.

Já com relação ao surgimento de novos gêneros, podemos dizer que esse processo se dá a partir das demandas sociais de interação, pois um gênero surge ou desaparece em função das condições sócio-discursivas. Nessa mesma perspectiva, Geraldi (2006) propõe que a emergência de novos gêneros está associada às atividades sociais, e que, quanto mais complexa é uma sociedade, mais complexos e em maior número são seus gêneros.

$\mathrm{Na}$ contemporaneidade, temos observado o surgimento e o desaparecimento de diversos gêneros. Rodrigues (2005) cita, como exemplo de gêneros que desapareceram de circulação social, a conversa de salão e o romancefolhetim. Já outros gêneros surgem de uma espécie de transmutação de outros gêneros, como, por exemplo, muitos dos gêneros encontrados no suporte digital: o $b \log ^{4}$, que lembra o diário, o e-mail, que possui características da carta. Todavia, os novos gêneros não substituem os já estabelecidos: o telefonema não substituiu a conversa e o artigo assinado não excluiu o editorial (RODRIGUES, 2005). Não se trata de uma relação de

\footnotetext{
${ }^{4}$ Blog pode ser traduzido por diário na rede. Sobre esse assunto ver: Komesu (2005).
} 
substituição entre gêneros, mas do aparecimento de gêneros a partir das novas necessidades de interlocução, o que ocorre através das mudanças sócio-históricas, repercutindo nas relações de subjetividade e alteridade dos sujeitos.

A origem dos gêneros, bem como seu processo de mudança, também é discutido por Todorov $(1980)^{5}$ no âmbito dos gêneros da esfera da literatura, porém essa reflexão também é válida para o presente estudo, uma vez que está em consonância com a teoria dos gêneros do discurso do Círculo de Bakhtin. Na perspectiva de Todorov (1980: 46), um "novo gênero é sempre a transformação de um ou de vários gêneros antigos". Ainda dentro do escopo literário, mas que pode ser ampliado para uma teoria geral dos gêneros, o autor pontua que, ao se pensar em temporalidade, não há nada "anterior aos gêneros", pois nunca houve literatura sem gênero. Como diz Bakhtin (2003), sempre falamos por meio de gêneros, pois todos os nossos enunciados são moldados segundo um gênero; por isso, segundo o autor, adquirimos conjuntamente as formas da língua e as formas do discurso (os gêneros).

Todorov propõe que tanto os gêneros literários quanto os gêneros das demais esferas sócio-discursivas têm por origem o discurso humano, e que sua constituição se dá a partir de práticas sociais. A mola propulsora do aparecimento ou desaparecimento de um gênero são as necessidades comunicativas intrínsecas às práticas de interação social. Somente as necessidades discursivas, surgidas nas interações humanas, propiciam o surgimento e modalizam os modos sociais de dizer, a saber, os gêneros do discurso.

Em resumo, os gêneros norteiam as interações sociais e, ao mesmo tempo, são por elas norteados; apresentam normatividade (mas também flexibilidade) para as organizações dos enunciados; servem como baliza para o dizer social; trazem, intrinsecamente, todo um universo axiológico. Isso porque os sujeitos se enunciam por meio dos enunciados, construídos dentro de um determinado gênero e, por meio do enunciado e de seu gênero, expressam suas concepções de mundo, suas crenças, seus valores, revelando, não raras vezes, a voz do outro que compõe seu discurso, formando, desse modo, uma cadeia ininterrupta de sentidos. Dessa maneira, compreendese a posição também central que os gêneros ocupam na arquitetura do pensamento do Círculo de Bakhtin.

\footnotetext{
${ }^{5}$ É importante ressaltar que Tzvetan Todorov foi um leitor de Bakhtin, embasando-se nesse autor para elaborar sua construção teórica sobre os gêneros do discurso. Contudo, no texto citado, Todorov não faz alusão à teoria bakhtiniana de gêneros.
} 


\section{PERCURSO METODOLÓGICO}

Como esta pesquisa insere-se nos estudos analíticos de gêneros e de discurso do Círculo de Bakhtin, também tomamos como fundamento metodológico a ordem metodológica de cunho sócio-histórico proposta por Bakhtin e Volochinov (2004) para o estudo da linguagem.

Além disso, também optamos pela proposta metodológica de estudo de gêneros do discurso de Rodrigues (2001), cujas ideias estão ancoradas em Bakhtin. Seguindo a proposta da autora, partimos da análise da "dimensão social do gênero para posteriormente analisarmos sua dimensão verbal [dimensãolinguageira]". Essa proposta aponta para a necessidade de estudar, de antemão, os aspectos sócio-discursivos do gênero, ou seja, o auditório social, as condições de produção, a esfera social em que circula, ${ }^{6}$ para, só então, proceder à análise de suas (relativas) regularidades linguageiras (no nosso caso, do verbo-visual), correlacionadas com as regularidades da situação social de interação. Entretanto, é importante salientar que esse procedimento de análise (a ordem de análise das dimensões do gênero, que, em dados momentos, são analisadas e apresentadas separadamente) justifica-se apenas por questões metodológicas, tendo em vista que as duas dimensões são indissociáveis na concretização do enunciado e, portanto, também do gênero. Segundo Rodrigues (2001: 248), "tem-se uma relação inextricável entre as dimensões social e verbal do enunciado, que formam a sua unidade, e do enunciado singular e o seu gênero".

Os dados da pesquisa constituem-se de todas as entrevistas pinguepongues, 52 entrevistas, publicadas em três revistas semanais de informação, de circulação nacional: CartaCapital, ISTOÉ e Veja, ${ }^{7}$ publicadas no período de 4 de outubro de 2006 a 8 de novembro de 2006, período de cobertura do segundo turno das eleições presidenciais no Brasil. Para este artigo, apresentaremos especificamente algumas regularidades da dimensão linguageira do gênero pesquisado, conforme mencionado.

\footnotetext{
${ }^{6}$ Como este artigo apresenta uma parte da totalidade da pesquisa realizada, as questões mais ligadas à dimensão social do gênero não serão discutidas aqui, embora o que apresentamos sobre a dimensão linguageira do gênero esteja assentado nos resultados de análise dos aspectos da dimensão social.

${ }^{7}$ As revistas são referenciadas pelo nome tal como ele aparece em suas capas: CartaCapital, sem espaço entre as palavras; ISTOÉ, em letra maiúscula e sem espaço entre as palavras; e Veja, com inicial maiúscula.
} 


\section{O GÊNERO ENTREVISTA PINGUE-PONGUE}

A opção pelo uso do termo entrevista pingue-pongue, ou seja, da nomeação do gênero objeto de pesquisa como entrevista pingue-pongue, ocorre em função da polissemia do termo entrevista, que pode indicar uma variedade de gêneros nomeados como tal (entrevista de emprego, entrevista médica, entrevista face a face etc.); além disso, esse é o termo mais recorrente na esfera de trabalho do jornalismo e, sobretudo, no jornalismo de revista, para identificar as entrevistas que apresentam textualmente a sequência de perguntas e respostas, que são resultado da reenunciação da entrevista face a face.

No jornalismo, segundo Oliveira (2002), a entrevista concretiza-se tanto na modalidade oral quanto na modalidade escrita. Na modalidade oral, é um importante gênero constitutivo da mídia radiofônica e televisiva. É comum, tanto no rádio quanto na TV, aparecer em forma de pergunta e resposta (pingue-pongue) entre entrevistador e entrevistado. No suporte jornal ou revista, também se realiza em forma de pergunta-resposta (pingue-pongue) (OLIVEIRA, 2002).

A entrevista pingue-pongue apresenta uma complexa relação discursiva entre entrevistador, editoria, entrevistado e leitor. Os interlocutores ocupam lugares diferenciados: quem pergunta (entrevistador), quem responde (entrevistado) e quem edita o texto. Mais que posições diferenciadas, tem-se um complexo processo de coautoria, pois editoria, entrevistador e entrevistado constroem o texto. Contudo, vale ressaltar que a definição do conteúdo, composição e estilo do gênero é definida pela esfera do jornalismo, a partir de uma linha editorial. Para Bonini (2000), a função interativa que se estabelece em qualquer entrevista jornalística é uma publicação em coautoria que deve trazer algo de novo sobre o entrevistado.

Assim, a entrevista pingue-pongue constitui-se a partir da edição/ reenunciação da interação direta (face a face) entre entrevistador e entrevistado, que foi gravada ou registrada em forma de anotações, e, mais recentemente, realizada através de $e$-mail. ${ }^{8}$ A partir dessa interação, no processo de reenunciação e retextualização final da entrevista face a face, há uma modalização da fala do entrevistado, isto é, a sua fala é um discurso

\footnotetext{
${ }^{8}$ Em seu artigo, Bonini (2000) discute as peculiaridades da interação que se estabelece entre entrevistador e entrevistado através da entrevista por e-mail, propondo estudar uma mídia que impõe um padrão diferenciado de interação, e que, consequentemente, apresenta uma textualidade distinta da entrevista clássica (face a face).
} 
citado dentro da fala do entrevistador, que dá o acabamento ao enunciado (a entrevista). O que dizem Bakhtin e Volochinov (2004) para o discurso relatado pode ser aqui aplicado, pois a fala do entrevistado, na reenunciação da entrevista pingue-pongue, é o discurso no discurso.

Desse modo, podemos dizer que o gênero entrevista pingue-pongue constitui-se como um discurso citado da entrevista face a face, ${ }^{9}$ ou seja, há um enquadramento do discurso do entrevistado a partir de uma reenunciação da entrevista face a face. Esse discurso citado pode ser considerado como "o discurso de outrem [do entrevistado] na linguagem de outrem [do autor], que serve para refratar a expressão das intenções do autor (BAKHTIN, 1998: 127).

Ainda sobre a análise da entrevista pingue-pongue, queremos fazer menção ao que Bakhtin diz acerca do discurso do outro no gênero romance:

No romance, o homem que fala e sua palavra são objeto tanto de representação verbal como literária. O discurso do sujeito falante no romance não é apenas transmitido ou reproduzido, mas representado artisticamente e, à diferença do drama, representado pelo próprio discurso (do autor). Porém a pessoa que fala e seu discurso constituem um objeto específico enquanto objeto do discurso: não se pode falar do discurso como se fala dos outros objetos [...] os objetos inanimados, os fenômenos, os acontecimentos, etc. (1998: 135).

Essa passagem do texto de Bakhtin se refere à "pessoa que fala no romance", em que há uma representação estética do discurso do outro. Já nos gêneros da "prosa extra-artística" (caso do nosso objeto de pesquisa), Bakhtin afirma haver um processo de transmissão do discurso do outro. Contudo, observamos que o discurso do "sujeito falante" na entrevista pingue-pongue não é apenas transmitido; há uma espécie de "encenação" da entrevista face a face, que, no entanto, é reenunciada e valorada pelo autor da entrevista pingue-pongue.

\footnotetext{
${ }^{9} \mathrm{~A}$ interação discursiva entre jornalista e entrevistado, que ocorre no momento da entrevista face a face, tanto pode ser reenunciada como entrevista pingue-pongue (objeto deste estudo), enunciado publicado em que a há a sequência de pergunta e resposta; como pode ser reenunciada em forma de discurso citado (reportado) do entrevistado que é inserido em outro gênero (por exemplo, notícia, reportagem, etc.). No caso de inserção do discurso citado do entrevistado em outro gênero, esse discurso passa a fazer parte de outra situação de interação discursiva, com objetivos discursivo-axiológicos diferenciados dos da entrevista pingue-pongue.
} 
E tendo em vista que, na entrevista pingue-pongue, o entrevistado e seu discurso constituem-se como objeto do discurso (quem é o entrevistado e o que ele diz), a valoração axiológica se sobressai, uma vez que esse entrevistado já vem envolvido em um "fundo" aperceptivo dos discursos alheios. Segundo Bakhtin (1998: 86), o objeto do discurso (no nosso caso, o entrevistado e seu discurso) "está amarrado e penetrado por idéias gerais, por pontos de vista, por apreciações de outros e por entonações".

Contudo, não é qualquer pessoa que pode assumir o ethos de entrevistado; essa "posição" é "outorgada" aos leitores que possuem uma relação assimétrica com os demais leitores; eles são "selecionados" a partir de seu papel social, que os qualifica para assumir a "posição de entrevistado".

Dessa forma, o "fio condutor" na entrevista é o entrevistado e seu discurso, em outras palavras, o que interessa, de fato, nesse gênero, é o entrevistado, cujo discurso, através do enquadramento feito pelo autor da entrevista, é "encharcado" de valoração, é "desacreditado", é "contestado" ou "enaltecido". Essa valoração dada ao entrevistado concretiza-se através de seu papel social, que é validado pelas "opiniões" sociais e pelos já-ditos sobre esse objeto (entrevistado). Isso nos remete à metáfora de "discurso-raio", utilizada por Bakhtin para explicar a orientação sobre o objeto do discurso:

Se representarmos a intenção, isto é, a orientação sobre o objeto de tal discurso pela forma de um raio, então nós explicaremos o jogo vivo e inimitável de cores e luzes nas facetas da imagem que é construída por elas, devido à refração do "discurso-raio" não no próprio objeto (como o jogo de imagem-tropo do discurso poético no sentido restrito, na "palavra isolada"), mas pela sua refração naquele meio de discursos alheios, de apreciações e de entonações através do qual passa o raio, dirigindo-se para o objeto. A atmosfera social do discurso que envolve o objeto faz brilhar as facetas de sua imagem (1998: 87).

Semelhantemente ao efeito de um raio, a atmosfera social do discurso que envolve o objeto faz brilhar as facetas de sua imagem, da mesma forma, os discursos que envolvem o entrevistado fazem com que os já-ditos sobre ele se intensifiquem, tenham ressonâncias ideológicas, constituindo a imagem da "personalidade fútil", do "político ético ou inescrupuloso", do "especialista" que é voz de autoridade etc. Em virtude disso, a valoração axiológica do jornalista na entrevista face a face, do autor da entrevista pingue-pongue e do próprio leitor sobre o entrevistado e seu discurso afloram de forma saliente no gênero. Trata-se de discursos "outros" sobre o objeto do discurso, cujas ressonâncias ideológicas se tornam intensas e "tensas" na textualização da entrevista. 
Essa reenunciação da entrevista face a face pode ser compreendida como um processo de intercalação de gênero, tendo em vista que os temas, o auditório social, a concepção de autoria sinalizam para a "presença" da interação face a face, que é reenunciada em forma de entrevista pinguepongue (enunciado publicado). Contudo, não se trata de uma presença explícita, pelo contrário, é como se fosse uma "encenação", demonstrando uma relação de constutividade genérica ${ }^{10}$ entre esses dois gêneros (entrevista face a face e entrevista pingue-pongue).

Por fim, evidenciamos, ainda, que o gênero entrevista pingue-pongue se materializa através de dois materiais semióticos: o verbal e o pictórico, tema que será analisado na seção seguinte.

\section{A ORGANIZAÇÃO TEXTUAL DA ENTREVISTA PINGUE-PONGUE"11}

A organização textual, como o nome já explicita, diz respeito aos elementos que compõem textualmente o gênero entrevista pingue-pongue, como título, subtítulo, introdução, sequência de perguntas e de respostas, "olho", fotografia etc. Nesta seção, abordaremos esse conjunto de elementos, bem como sua sequenciação na organização da dimensão linguageira do gênero (materialidade do gênero).

Inicialmente, vale salientar que durante a análise dos dados percebemos manifestações diferenciadas do gênero nas revistas pesquisadas (no que se refere ao seu lugar na revista e seu papel no todo da revista), que refletiam a relevância e a valoração dadas ao entrevistado e seu discurso. Em virtude disso, fizemos o seguinte agrupamento das entrevistas:

1. Entrevistas pingue-pongues nucleares: publicadas nas páginas vermelhas e nas seções principais da revista ISTOÉ; nas páginas amarelas e seções principais da revista da Veja; e em qualquer seção na CartaCapital.

2. Entrevistas pingue-pongues satélites: ${ }^{12}$ publicadas em seções diversas, como, por exemplo, nas seções destinadas a colunismo social (Holofote

\footnotetext{
10 "Capturar" o processo axiológico-discursivo de reenunciação da entrevista face a face, discutindo a relação de dependência constitutiva entre esta e a entrevista pingue-pongue, é um dos objetivos de pesquisa de doutorado em andamento de Nívea Rohling da Silva.

${ }^{11}$ A noção de organização textual está relacionada à composição do gênero de Bakhtin. Porém a composição do gênero nos termos bakhtinianos é mais ampla que a noção de organização (ou composição) textual, uma vez que inclui os aspectos da dimensão social, como a composição dos participantes da interação. Usamos o termo organização textual por estarmos apresentando apenas uma faceta, a textual, da noção de composição do gênero.

${ }^{12}$ As entrevistas pingue-pongues satélites não são publicadas pela revista CartaCapital.
} 
(Veja) e Gente (Veja)); nas seções dedicadas a discutir "acontecimentos" políticos da semana (Brasil Confidencial (ISTOÉ)); e nas seções que discutem comportamento, profissão, saúde etc. (seção GUIA Veja (Veja)). Nessas seções, a entrevista cumpre a tarefa de "completar" e/ou "reafirmar" outros enunciados, como reportagens.

O critério para esse agrupamento das entrevistas, como já mencionado, foi estabelecido a partir da percepção de que, nas variadas manifestações do gênero nas edições pesquisadas, algumas entrevistas se encontravam em uma posição de "independência" em relação aos demais gêneros e ocupavam, nesses casos, uma página ou até mesmo uma seção da revista, o que nos levou a nomear esse conjunto de entrevistas como entrevista nuclear. Já em outros casos, o gênero se encontrava em posição de "subordinação" a outros gêneros em uma mesma página da revista e, consequentemente, em uma mesma seção; a esse conjunto, atribuímos o nome de entrevista satélite.

Além disso, após analisar os elementos constitutivos do gênero e sua organização na materialidade do texto, agrupamos as entrevistas em duas tabelas, de acordo com suas similaridades: a Tabela 1 apresenta a organização textual da entrevista nuclear nas diferentes revistas e a Tabela 2 apresenta a organização textual da entrevista satélite (ISTOÉ e Veja).

\begin{tabular}{|c|c|c|}
\hline CartaCapital & ISTOÉ & Veja \\
\hline Nome da seção (variável) & $\begin{array}{l}\text { Nome da seção (no caso: } \\
\text { Entrevista) e nome do } \\
\text { entrevistado (na mesma linha) }\end{array}$ & $\begin{array}{l}\text { Nome da seção (no caso: } \\
\text { Entrevista) e nome do } \\
\text { entrevistado (na mesma linha) }\end{array}$ \\
\hline Título & Título & Título \\
\hline Subtítulo e foto do entrevistado & Subtítulo e foto do entrevistado & Subtítulo e foto do entrevistado \\
\hline Nome do jornalista & Nome do jornalista & Nome do jornalista \\
\hline Introdução & Introdução & Introdução \\
\hline $\begin{array}{l}\text { Sequência de perguntas e res- } \\
\text { postas: as perguntas, primeira- } \\
\text { mente, introduzidas com o nome } \\
\text { da revista e, depois, somente pelas } \\
\text { iniciais da revista; e respostas } \\
\text { (introduzidas com o nome do } \\
\text { entrevistado). Há intercalação de } \\
\text { "olho" e fotografias. A entrevista é } \\
\text { apresentada em colunas. Não há } \\
\text { inserção de gêneros da esfera da } \\
\text { propaganda. }\end{array}$ & $\begin{array}{l}\text { Sequência de perguntas e res- } \\
\text { postas: perguntas (introduzidas } \\
\text { comonomedarevista) erespostas } \\
\text { (introduzidas com o nome do } \\
\text { entrevistado). Há intercalação de } \\
\text { "olho" e fotografias. A entrevista } \\
\text { se apresenta em colunas. As } \\
\text { bordas das páginas são impressas } \\
\text { na cor vermelha em um fundo } \\
\text { branco. Há inserção de gêneros } \\
\text { da esfera da propaganda, que } \\
\text { ocupam um espaço de destaque } \\
\text { dentro da entrevista. }\end{array}$ & $\begin{array}{l}\text { Sequência de perguntas e res- } \\
\text { postas: perguntas (introduzidas } \\
\text { comonomedarevista) erespostas } \\
\text { (introduzidas através do nome do } \\
\text { entrevistado). Há intercalação de } \\
\text { "olho" e fotografias. A entrevista } \\
\text { apresenta-se em colunas. A } \\
\text { entrevista é publicada em folha } \\
\text { de cor amarela. Há inserção de } \\
\text { gêneros da esfera da propaganda, } \\
\text { que ocupam um espaço de } \\
\text { destaque dentro da entrevista. }\end{array}$ \\
\hline
\end{tabular}

Tabela 1 - Organização textual da entrevista pingue-pongue nuclear. 
Os dados apresentados na Tabela 1 revelam que a entrevista nuclear apresenta uma relativa estabilidade em sua organização textual, a qual não se altera significativamente de uma edição para outra, ou de revista para revista. Entretanto, podem ocorrer algumas alterações com relação à diagramação, ou seja, elementos como a fotografia do entrevistado, o título, o subtítulo, dentre outros, podem receber diagramações diferenciadas, mas a presença desses elementos, bem como sua "sequência" no texto, sofrem pouca variação. Portanto, há uma relativa estabilidade na organização textual do gênero, que obedece à seguinte sequenciação textual:

a) Inserção do nome da seção e do nome do entrevistado - o nome da seção em que está inserida a entrevista aparece na parte superior da página e, na mesma linha, há a inserção do nome do entrevistado;

b) Inserção do título - o título está interligado ao conteúdo semânticoobjetal da entrevista; em algumas situações, ele constitui-se em um "olho"; algo que foi dito pelo entrevistado e que está inserido na entrevista;

c) Inserção do nome do jornalista - aparece com menos destaque; essa "assinatura" do jornalista sinaliza a autoria;

d) Inserção de introdução - a introdução contextualiza o entrevistado, destacando seu papel social, suas realizações e o assunto/tema sobre o qual ele se pronuncia;

e) Inserção de sequência de perguntas e respostas - introduzidas, respectivamente, pelo nome da revista e pelo nome do entrevistado. Há, nessa sequência, a intercalação de "olhos" e fotografia(s) do entrevistado.

Já a entrevista satélite apresenta a seguinte organização textual:

\begin{tabular}{|c|}
\hline Elementos da organização textual das entrevistas pingue-pongues satélites \\
\hline Título \\
\hline Introdução (reduzida) \\
\hline Pergunta e resposta (introduzidas com o nome da revista e do entrevistado) \\
\hline Foto do entrevistado (ao final da entrevista ou nas margens laterais) \\
\hline Frase de fechamento \\
\hline
\end{tabular}

Tabela 2 - Organização textual da entrevista pingue-pongue satélite.

A Tabela 2, diferentemente do que aconteceu com a Tabela 1, não foi subdivida por revistas porque nas publicações das revistas ISTOÉ e Veja a organização apresenta a mesma sequência de elementos. A organização textual da entrevista satélite também se caracteriza fundamentalmente pela 
"estrutura" pergunta-resposta, porém não contempla todos os elementos observados na entrevista nuclear. Isso ocorre em virtude do espaço reduzido que ocupa na revista, o que, consequentemente, constitui-se em um índice valorativo. Essa organização textual compreende a seguinte sequência de elementos:

a) Inserção do título da entrevista - constitui-se de um "olho";

b) Inserção de introdução - a introdução apresenta o entrevistado e o "teor" da entrevista; também faz menção ao nome do jornalista, que é, na maioria das vezes, identificado como "repórter";

c) Inserção de sequência de perguntas e respostas - em alguns casos, as perguntas e respostas são introduzidas, respectivamente, pelo nome da revista e pelo nome do entrevistado; contudo, em outras situações, inexiste a inserção do nome da revista e do nome do entrevistado;

d) Inserção de foto do entrevistado - a fotografia do entrevistado geralmente se situa na lateral direita do texto ou na parte inferior da entrevista;

e) Inserção de uma frase de "fechamento".

Ainda, na organização textual (cf. Tabela 1), constatamos a inserção, ou melhor, a "invasão" de gêneros da propaganda na entrevista pinguepongue, que consideramos um gênero "parasitário" nessa situação, uma vez que impõe sua presença no fluxo da leitura da entrevista. Há também a presença de outros materiais semióticos além do verbal, que nomeamos como material semiótico pictórico ou visual (cores, diagramação das letras, fotografia etc.). Tendo em vista a importância da questão verbo-visual na constituição do nosso objeto de estudo, apresentaremos, na seção seguinte, a análise de seu papel na entrevista pingue-pongue.

\section{A QUESTÃO DO VERBO-VISUAL NA ENTREVISTA PINGUE-PONGUE}

A entrevista pingue-pongue, como mencionado, materializa-se por meio de duas modalidades semióticas: a verbal e a pictórica, cuja articulação na organização textual também é responsável pela construção dos sentidos das/ nas entrevistas. O material semiótico pictórico é constituído por elementos como as fotografias, as cores das páginas e também a disposição gráfica dos elementos no texto/enunciado.

Dentre os elementos mencionados, o que mais se destaca nesse gênero é a fotografia, que, na esfera do jornalismo, normalmente integra também os gêneros notícia e reportagem e é chamada de fotojornalismo. Brait (2004: 47) observa que "a técnica fotográfica assegura o simulacro visual 
do acontecimento, [pois] cria-se o efeito de objetividade, de transparência, como se não houvesse um enunciador". Mas, apesar desse apagamento do enunciador, a autora salienta que, na verdade, a construção da cena enunciativa revela a existência de um sujeito da enunciação e isso ocorre, segundo a autora, porque

o enquadramento, o dimensionamento da luz e outros recursos da linguagem fotográfica funcionam discursivamente, isto é, não têm um valor em si, enquanto signos de um sistema de comunicação e significação, mas assinalam escolhas de um sujeito, tendo em vista o discurso a ser construído e os efeitos de sentido que devem ser produzidos no enunciatário (BRAIT, 2004: 47).

Já a fotografia que está incorporada à entrevista pingue-pongue tem uma função diferente da dos gêneros notícia e reportagem, pois ela não tem por objetivo "capturar" e valorar um "fato" propriamente dito, mas apresentar, na maioria dos casos, foto(s) do entrevistado e de outros elementos relacionados ao horizonte temático da entrevista em particular (embora também valoradas discursivamente). A fotografia do entrevistado é um elemento constitutivo do gênero, haja vista que em todas as incidências dos dados de pesquisa constatamos a inserção de uma ou mais fotografias da pessoa entrevistada. Isso ocorre porque é ela (a fotografia) que reforça e impulsiona o leitor para a leitura das entrevistas, uma vez que, ao visualizar uma fotografia "destacada" como objeto discursivo (o entrevistado), o leitor pode se sentir impelido a ler (ou não) a entrevista.

Além de atrair a atenção do leitor, a fotografia também é um lugar da materialização da valoração axiológica, pois, dependendo da foto publicada, ela ou "depõe contra" o entrevistado, ou o exalta, tendo em vista seu papel social e a intenção interlocutiva do autor da foto e da entrevista (e da instância jornalística). Portanto, a escolha desse elemento pictórico, que ajuda a compor a dimensão linguageira do gênero, corrobora com o projeto discursivo do autor da entrevista, o que equivale a dizer que não se trata de uma escolha "neutra" ou "aleatória", mas de um trabalho estilísticocomposicional pertencente ao domínio da autoria. Segundo Vannuchi (2007a), na parte final de "produção", após a edição gráfica, a entrevista retorna à editoria para que sejam feitos os últimos ajustes necessários para a apresentação visual do texto, ou seja, algum corte que ainda seja necessário, a composição das legendas das fotos etc. Assim, a articulação entre os elementos verbais e pictóricos (principalmente os fotográficos) faz parte do acabamento estilístico-composicional do gênero. 
Entretanto, é preciso salientar que a fotografia não é apenas um dos materiais semióticos da entrevista pingue-pongue; ela também é a materialização de um enunciado citado, de um já-dito, que é reenunciado e enquadrado na entrevista para fazer parte do projeto discursivo do gênero. Assim, consideramos a fotografia inserida em uma entrevista como um enunciado dentro de outro enunciado, ou seja, como um discurso citado, tendo em vista que ela também possui seu próprio projeto discursivo, com sua concepção de autor e de interlocutor; ela é um enunciado. Na entrevista, há a inserção tanto de fotografias de arquivo, ou seja, de fotografias "tiradas" em outra situação social de interação para cumprir outros propósitos discursivos, quanto de fotografias "tiradas" no momento da entrevista face a face. ${ }^{13}$

Na sequência, apresentaremos a articulação do verbo-visual no gênero entrevista pingue-pongue por meio de análise de uma entrevista em particular, cujo entrevistado é o escritor João Ubaldo Ribeiro. Por questões de ordem prática, tendo em vista a impossibilidade de reproduzir uma entrevista de cinco páginas no corpo deste artigo, apresentaremos cada página dessa entrevista separadamente, com exceção das páginas em que se insere a propaganda; neste caso, juntamos duas páginas em um só espaço, uma vez que, neste artigo, não analisaremos o papel da intercalação de propagandas na entrevista.

A entrevista com o escritor João Ubaldo Ribeiro (ISTOÉ, n. 1930, 2006) foi publicada na seção de entrevistas (páginas vermelhas) em uma edição anterior ao segundo turno das eleições presidenciais. Tendo em vista a época da publicação, o assunto que se sobressai é a posição do entrevistado sobre a eleição presidencial. A entrevista é "percebida" pelo leitor como um todo, ou seja, ela é considerada como um único enunciado, que é constituído pelo material verbal e pelo material pictórico, articulados através da diagramação, quer dizer, pela forma como os elementos verbais e pictóricos estão distribuídos nas páginas da entrevista, que, por sua vez, é uma das facetas do acabamento do enunciado. Toda a entrevista é "emoldurada" por bordas vermelhas, o que justifica o "apelido" de "páginas vermelhas" que essa seção recebe na redação da revista (VANNUCHI, 2006). Os elementos que integram a entrevista são (em sequência):

\footnotetext{
${ }^{13}$ Isso é uma prática recorrente no jornalismo, haja vista a inserção de fotografias "assinadas" por diferentes fotógrafos em uma mesma entrevista.
} 


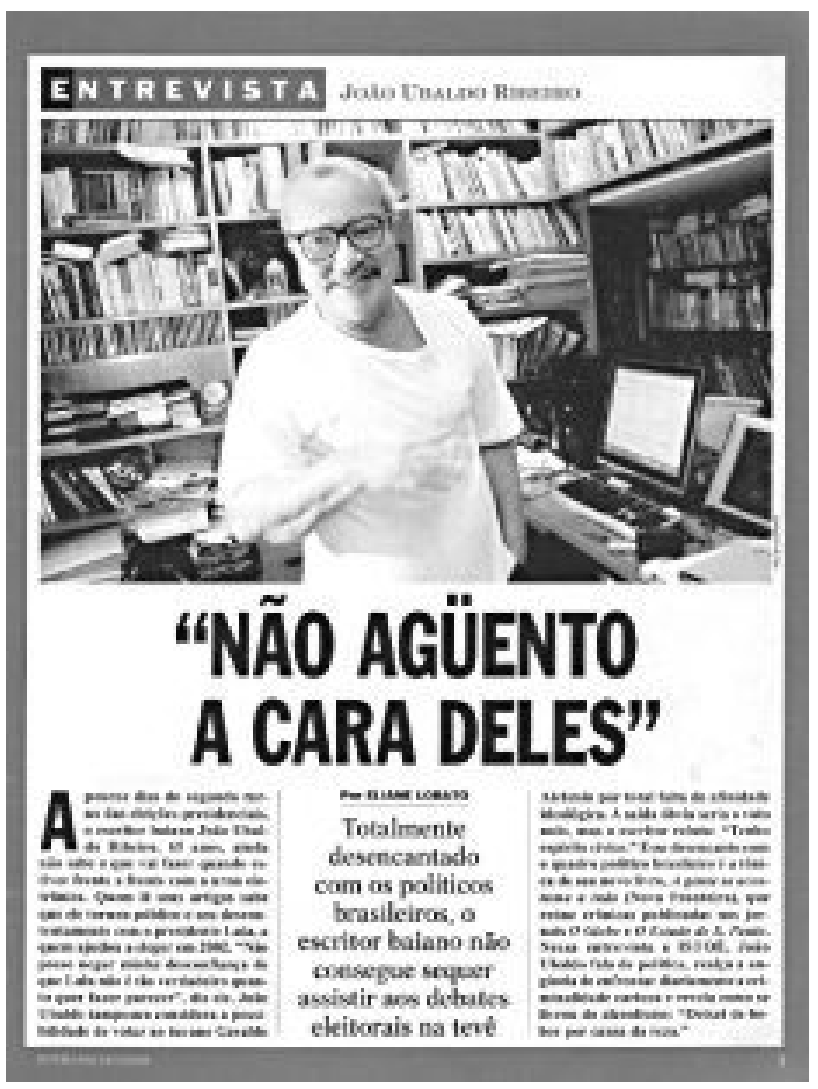

Figura 1 - Primeira página da entrevista com João Ubaldo Ribeiro (ISTOÉ).

a) Inserção do nome da seção da revista e do nome do entrevistado (Entrevista - João Ubaldo Ribeiro) - ocupa a parte superior da entrevista e se destaca pelo tamanho e pela forma das letras;

b) Inserção de uma fotografia colorida do entrevistado - é o elemento de maior destaque na primeira página. A fotografia insere o entrevistado em seu "ambiente" de trabalho (escritório), pois, ao fundo, percebemos a presença de livros e de um computador. Como a imagem "mostra" o ambiente de trabalho do entrevistado, ela conduz o leitor a relacionar essa fotografia com o papel social de intelectual (escritor) do entrevistado. $\mathrm{Na}$ extremidade direita, a fotografia recebe a "assinatura" do fotógrafo (Hélio Nagamine); 
c) Inserção de título ("NÃO AGÜENTO A CARA DELES") - o título aparece bem destacado, com letras maiúsculas, centralizado; ele éconstruído a partir de um "olho", que, segundo Vannuchi (2007b), constitui-se em uma frase dita pelo entrevistado e que é colocada em destaque, pelo autor da entrevista. Ao "retirar" do corpo do texto um trecho de uma "fala" e inserilo no título, temos um caso de bivocalidade, uma vez que percebemos duas vozes que se materializam nesse novo enunciado. Há a voz do entrevistado, que efetivamente diz "Não agüento a cara deles" e a voz do autor, que quer ressaltar essa posição valorativa do entrevistado; esse destacamento de um trecho da fala do entrevistado também é um ato valorativo, pois a escolha demanda destaque para certas partes da fala do entrevistado e exclusão de outras;

d) Inserção do nome do jornalista (Por ELIANE LOBATO) - em letra maiúscula, mas com menor destaque;

e) Inserção de introdução e subtítulo - em três colunas insere-se a introdução, que apresenta o entrevistado ("escritor baiano João Ubaldo Ribeiro, 65 anos") e, na sequência, os "assuntos" abordados na entrevista: 1. O descontentamento do entrevistado para com os políticos brasileiros ("ainda não sabe o que vai fazer quando estiver frente a frente com a urna eletrônica"); 2. A criminalidade ("realça a angústia da criminalidade carioca"); 3. A relação do entrevistado com o álcool ("revela como se livrou do alcoolismo"). Como podemos perceber, a introdução faz uma espécie de apresentação e resumo da entrevista e, de certa forma, "simula" a apresentação que geralmente o jornalista faz do entrevistado na entrevista da mídia televisiva ou radiofônica. "Encaixada" na introdução, há a inserção de uma frase do entrevistado, que se constitui em um subtítulo: "Totalmente desencantado com os políticos brasileiros, o escritor baiano não consegue sequer assistir aos debates eleitorais na tevê". O subtítulo acentua a temática do segundo turno das eleições presidenciais e "expõe" a valoração do entrevistado em relação ao referido tema. 

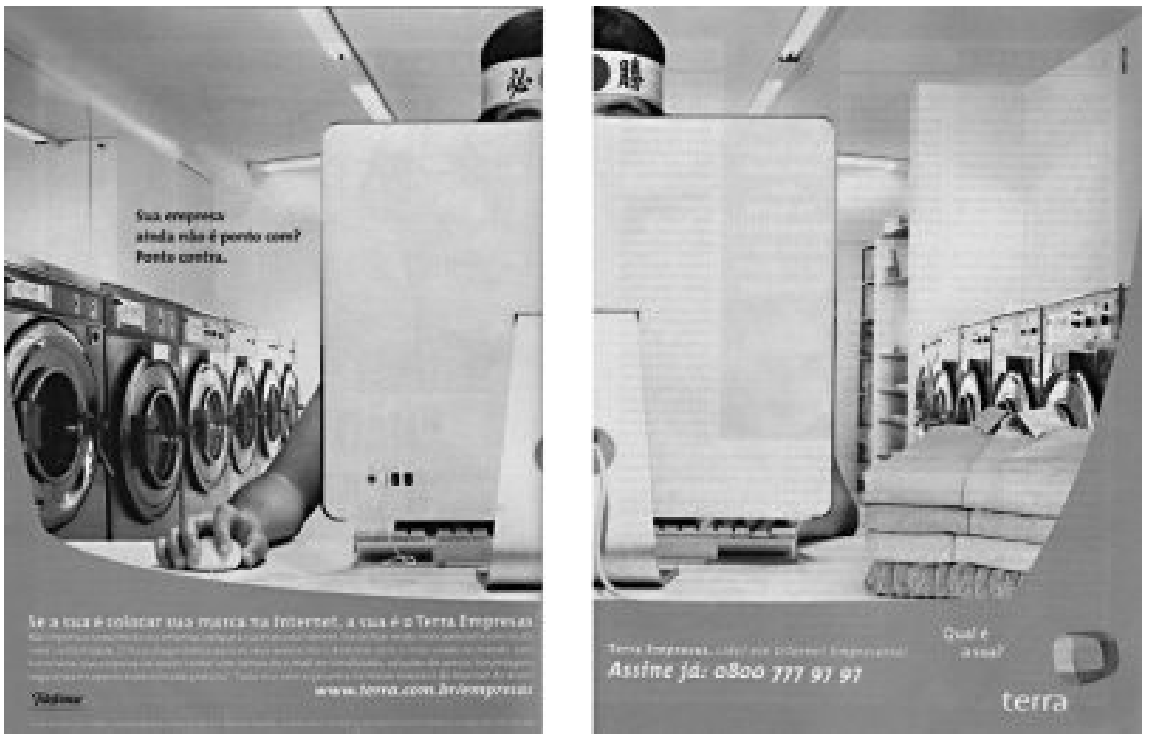

Figura 2 - A inserção de gênero da esfera da propaganda na entrevista com João Ubaldo Ribeiro (ISTOÉ).

Inserção de propaganda - ocupa página dupla, ou seja, a segunda e a terceira páginas da entrevista. Trata-se de uma propaganda do provedor de Internet Terra. 


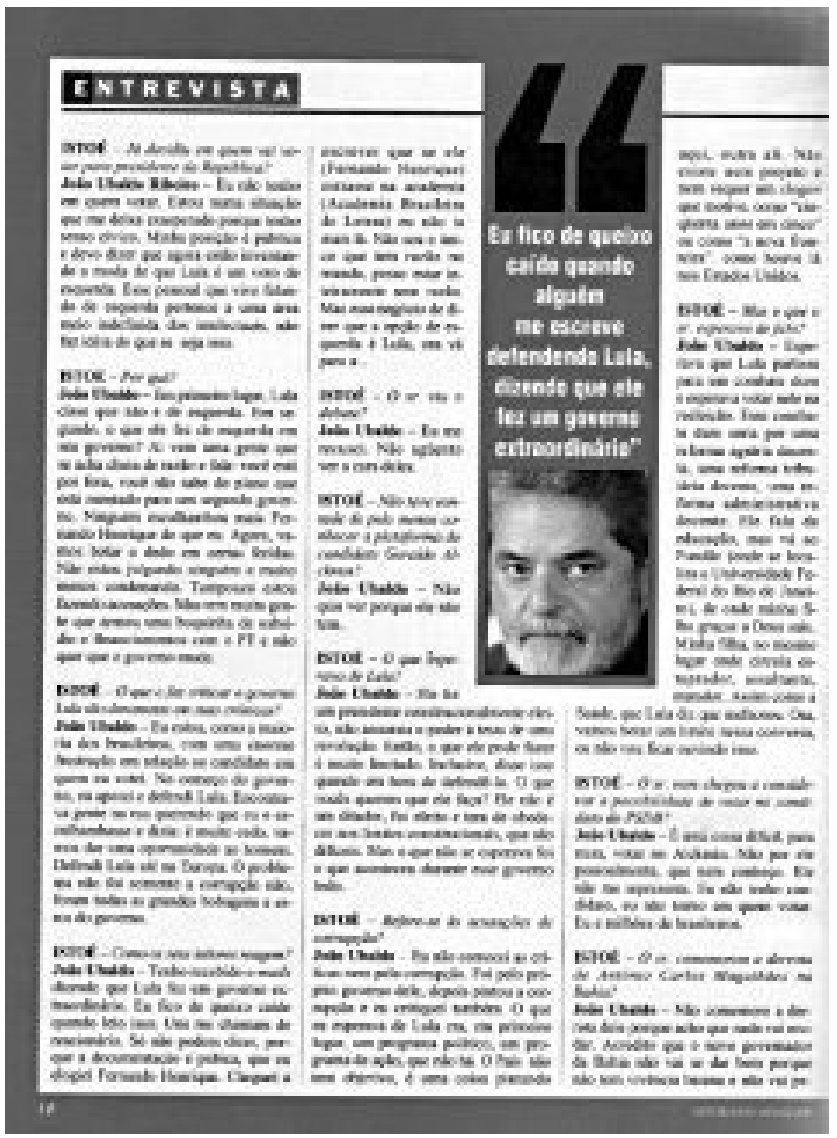

Figura 3 - Quarta página da entrevista com João Ubaldo Ribeiro (ISTOÉ).

a) Inserção do nome da seção (ENTREVISTA) - indicação do nome da seção em letra maiúscula sobre fundo preto e vermelho;

b) Inserção da sequência de perguntas e respostas - é justamente dessa sequência que se originou o termo entrevista pingue-pongue, pois ela "simula" as perguntas e respostas da entrevista face a face. A pergunta é introduzida pelo nome da revista, que aparece em letras maiúsculas e destacado em negrito (ISTOÉ). A resposta é introduzida pelo nome completo do entrevistado, em letras minúsculas e destacado em negrito; somente na primeira inserção do nome do entrevistado é que é utilizado o 
nome completo (João Ubaldo Ribeiro), pois, da segunda inserção em diante, aparece somente o pré-nome (João Ubaldo), o que sugere um "ar" de já-dito, de conhecido e de intimidade com o entrevistado, uma vez que a escolha poderia ter recaído pela retomada do sobrenome do autor;

c) Inserção de "olho" ("Eu fico de queixo caído quando alguém me escreve defendendo Lula, dizendo que ele fez um governo extraordinário") - as primeiras linhas de abertura, as quais indicam que é uma "fala" do entrevistado que está integrando o "conteúdo" da entrevista, são destacadas através de ampliação da fonte e estão impressas na cor preta; as aspas de fechamento são apresentadas em fonte menor, na cor branca;

d) Inserção de fotografia do candidato à Presidência Luiz Inácio Lula da Silva - o autor da entrevista insere, logo abaixo do "olho", a fotografia de uma pessoa citada na entrevista (o candidato à Presidência Luiz Inácio Lula da Silva). Trata-se de uma fotografia colorida e pequena, em que o candidato aparece em tom "sério"; e, ao contrário da foto anterior, esta não explicita a "assinatura". A intercalação de outra fotografia, que não a do entrevistado, é uma particularidade da revista ISTOÉ e, em alguns casos, da revista CartaCapital. Já nas entrevistas das páginas amarelas da revista Veja, constatamos somente a presença de uma única fotografia, do entrevistado. A maneira como a fotografia do presidente e candidato Lula está diagramada, em que ele é mostrado de forma a exprimir um "tom" oblíquo, confere a ele uma expressão de dúvida, de fragilidade, de defesa. A forma como o projeto gráfico seleciona essa foto, e não outra, e a articula com os demais elementos verbais (por exemplo, o título "Não agüento a cara deles") e com o "olho" ("eu fico de queixo caído quando alguém me escreve defendendo Lula, dizendo que ele fez um governo extraordinário"), possibilita ao leitoreleitor capturar efeitos de sentido que vão além do objetivo discursivo de "ilustrar" a entrevista, adentrando caminhos em direção à materialização ideológica de posições políticas. A relação entre o material linguístico e o material pictórico cria efeitos de sentidos, resultados de posições axiológicas da autoria do gênero. 


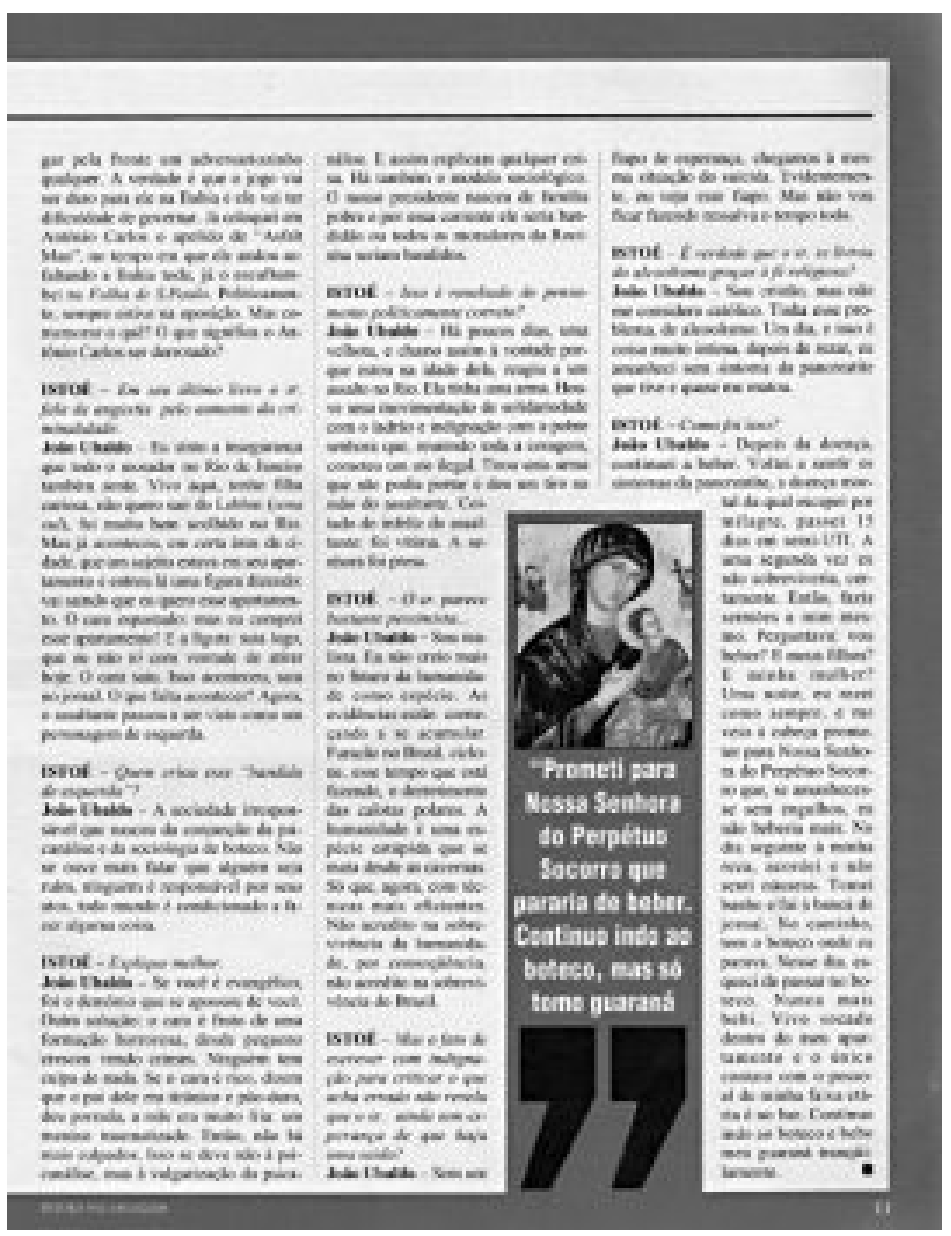

Figura 4 - Quinta página da entrevista com João Ubaldo Ribeiro (ISTOÉ).

a) Inserção da sequência de perguntas e respostas;

b) Inserção de imagem - é inserida a imagem de Nossa Senhora do Perpétuo Socorro, mas, nesse caso, não se trata de uma fotografia, mas de uma réplica de pintura. A imagem da Santa é inserida na entrevista, uma vez que o entrevistado a cita, atribuindo a ela sua decisão de ter "se livrado do alcoolismo". Da mesma maneira que a fotografia do presidente Lula, a imagem da Santa se refere a um "outro" inserido na entrevista; 
c) Inserção de "olho" ("Prometi para Nossa Senhora do Perpétuo Socorro que pararia de beber. Continuo indo ao boteco, mas só tomo guaraná.") logo abaixo da imagem da Santa.

A análise da articulação entre elementos verbais e visuais na entrevista pingue-pongue mostrou que a inter-relação desses elementos contribui significativamente para a constituição do gênero, e que, dentre os elementos pictóricos supracitados (cor, disposição gráfica dos elementos etc.), a fotografia do entrevistado é o mais "saliente" no gênero. Isso se comprova pelo fato de que em todas as incidências do gênero há pelo menos uma fotografia do entrevistado. É ela a responsável por "atrair" a atenção do leitor para que ele leia a entrevista, concretizando assim a interação discursiva entre autor e leitor, além de atribuir valoração axiológica à pessoa do entrevistado.

Pudemos observar que a fotografia (bem como os demais elementos pictóricos) não se constitui em um elemento meramente ilustrativo. Trata-se, pois, de um importante aspecto que é responsável pelas relações dialógicas no enunciado e pela materialização dos acentos de valor atribuídos ao entrevistado e ao tema de seu discurso, conforme apresentado na seção de análise. Assim, a inserção de foto(s) do entrevistado e de outros elementos relacionados ao horizonte temático da entrevista em particular constitui o enunciado (e o gênero) e corrobora para a produção de efeitos de sentido na comunicação discursiva que se realiza por meio da entrevista.

\section{CONSIDERAÇÕES FINAIS}

Procuramos, neste trabalho, apresentar algumas regularidades observadas na análise da dimensão linguageira do gênero entrevista pingue-pongue, do jornalismo de revista, em especial, a inter-relação dos elementos verbais e pictóricos (verbo-visual) na entrevista.

Demonstramos que o gênero entrevista pingue-pongue se materializa através de dois materiais semióticos: o verbal e o pictórico. O elemento pictórico que se sobressaiu na análise dos dados foi a fotografia, tendo em vista que esta se faz presente em todos os enunciados do gênero que compuseram os dados de pesquisa. Mostramos também que esse caráter multimodal do gênero amplia os sentidos discursivo-axiológicos materializados nos enunciados e pode se constituir em uma área fértil para novas pesquisas. 


\section{REFERÊNCIAS BIBLIOGRÁFICAS}

BAKHTIN, M. M. Estética da criação verbal. Trad. do russo por Paulo Bezerra. 4. ed. São Paulo: Martins Fontes, 2003.

BAKHTIN, M.; VOLOCHINOV, V. N. Marxismo e filosofia da linguagem: problemas fundamentais do método sociológico na ciência da linguagem. Trad. do francês por Michel Lahud e Yara F. Vieira. 11. ed. São Paulo: Hucitec, 2004.

BONINI, Adair. Entrevista por e-mail: pragmática de um gênero (des) conhecido ou problemas comunicativos na variação do gênero. Revista de Letras, Fortaleza - CE, v. 22, n. 1/2, p. 5-13, 2000.

BRAIT, Beth. A construção do sentido: exemplo fotográfico persuasivo. Líbero, São Paulo, v. 6, n. 11, p. 44-49, 2004.

GERALDI, João Wanderley. [Curso ministrado] Seminário Bakhtin: linguagem e sujeito, entre a ética e a estética. Florianópolis: Universidade Federal de Santa Catarina, 2006.

KOMESU, F. C. Blogs e as práticas de escrita sobre si na Internet. In: MARCUSCHI, L. A.; XAVIER, A. C. (Org.). Hipertexto e gêneros digitais: novas formas de construção do sentido. Rio de Janeiro: Lucerna, 2005. p. 110-119.

OLIVEIRA, Ana Tereza Pinto de. O gênero entrevista na imprensa escrita e sua relação com as modalidades da língua. 2002. Disponível em: $<$ http://www.fiamfaam.br/comunicacao/projetos/inovacoes/idademidia/ pdfs/art_111-16_im1.pdf>. Acesso em: 15 jul. 2006.

RIBEIRO, João Ubaldo. Não agüento a cara deles. ISTOÉ, São Paulo: Três Editorial, n. 1930, 18 out. 2006.

RODRIGUES. Rosângela Hammes. A constituição e o funcionamento do gênero jornalístico artigo: cronotopo e dialogismo. Tese (Doutorado em Linguística Aplicada e Estudos da Linguagem ) - Pontifícia Universidade Católica de São Paulo, 2001. 
RODRIGUES. Rosângela Hammes. Osgêneros dodiscurso naperspectiva dialógica da linguagem: a abordagem de Bakhtin. In: MEURER, José Luiz; BONINI, Adair; MOTA-ROTH, Désirée (Org.). Gêneros: teorias, métodos e debates. São Paulo: Parábola Editorial, 2005. p. 152-183.

ROJO, Roxane. Gêneros do discurso e gêneros textuais: questões teóricas e aplicadas. In: MEURER, José Luiz; BONINI, Adair; MOTA-ROTH, Désirée (Org.). Gêneros: teorias, métodos e debates. São Paulo: Parábola Editorial, 2005. p. 184-207.

SANT'ANNA, A. Propaganda: teoria-técnica-prática. 7. ed. São Paulo: Pioneira, 2001.

SILVA, Nívea Rohling da. O gênero entrevista pingue-pongue: reenunciação, enquadramento e valoração do discurso do outro. Dissertação (Mestrado) - Universidade Federal de Santa Catarina, Florianópolis, 2007.

TODOROV, Tzvetan. Os gêneros do discurso. São Paulo: Martins Fontes, 1980.

VANNUCHI, Camilo. A entrevista pingue-pongue no jornalismo de revista. Entrevista concedida via e-mail em 12 set. 2006.

VANNUCHI, Camilo. Condições de produção de uma revista semanal. Entrevista concedida via e-mail em 02 fev. 2007a.

VANNUCHI, Camilo. Processo de produção da entrevista pingue-pongue. Entrevista concedida via e-mail em 03 maio 2007b.

VOLOCHINOV, V. N.; BAKHTIN, M. M. Discurso na vida e discurso na arte (sobre a poética sociológica). Trad. inédita de Carlos Alberto Faraco e Cristóvão Tezza [para fins didáticos]. Versão da língua inglesa de I. R. Titunik a partir do original russo, 1926. 